\title{
Propylenated fatty acids as emulsifiers
}

\author{
By Y. El-Shattory, Saadia M. Aly and M.G. Megahed \\ Fats and Oils Department, National Research Centre, Dokki, Cairo, Egypt.
}

\section{RESUMEN}

Acidos grasos propilenados como emulsionantes.

Se prepararon estearato, palmitato, laurato, oleato y linoleato de hidroxipropilenilos mediante reacción de oxido de propileno con ácido graso a $160^{\circ} \mathrm{C}$ durante cinco horas de agitación en presencia de hidróxido potásico como catalizador. Se determinaron las propiedades físico-químicas de los cinco productos, en cuanto a su uso como emulsionantes.

PALABRAS-CLAVE: Acido graso propilenado - Emulsionante alimentario - Propiedades físicas - Propiedades químicas.

\section{SUMMARY}

\section{Propylenated fatty acids as emulsifiers.}

Hydroxy propylenyl stearate, palmitate, laurate, oleate and linoleate were prepared by reaction of propylene oxide with fatty acid at $160^{\circ} \mathrm{C}$ for five hours stirring in presence of potassium hydroxide as a catalyst. Physico-chemical properties of the five products, regarding their use as emulsifiers, were determined.

KEY-WORDS: Chemical properties - Food emulsifier - Physical properties - Propylenated fatty acid.

\section{INTRODUCTION}

In general, for a surfactant to act as an emulsifier, it must show good surface activity and produce a low interfacial tension in the particular system in which it is to be used. This means that it must have a tendency to migrate to the interface, rather than to remain dissolved in either one of the bulk phases (1). The emulsifiers were used to improve bread volume and texture, to extend shelf-life, and to control cookers spread factor (2). Various food products, such as butter, low fat spreads, shortening, chocolate, and margarine are water- in - oil (W/O) emulsions and require emulsifiers to prevent separation (3-5). The degree of solubility of surfactants in water often suggests approximate hydrophilic lipophilic balance (HLB) values are indicators of behavioral characteristics and do not indicate emulsifying efficiency. The selection of a suitable emulsifier for an $\mathrm{O} / \mathrm{W}$ or a W/O emulsion must be determined by experimentation. However a low HLB value (3-6) will promote or stabilize W/O emulsion, an intermediate HLB value (8-13) will stabilize $\mathrm{O} / \mathrm{W}$ emulsion, and a high HLB value (15-18) will act as a solubilizer (6).

\section{MATERIAL AND METHOD}

- Hydroxy propylenyl fatty acids were prepared by adding propylene oxide slowly to fatty acid at $160^{\circ} \mathrm{C}$ while stirring for five hours.

- $\mathrm{pH}$ was measured with a $\mathrm{pH}$ meter (Corian model SA 520).

- Surface tension was measured in distilled water at room temperature $\left(15^{\circ} \mathrm{C}\right)$ with a (Sc-Du Nouy Interfacial Tensiometer Model 70545) (7).

- HLB was determined as described in (9).

- Viscosity and shear stress were determined with Bohlin Visco $88 \mathrm{~B} \mathrm{v}$ according to (10).

- Solubility was determined in different solvents, as water, ether, petroleum ether (40/60), $\mathrm{n}$-Hexane, oil and ethanol.

- Emulsifying power was determined according to Titus (11).

- Infrared (IR) spectra were determined with Backman according to (12).

\section{RESULTS AND DISCUSSION}

The solubility of the mentioned emulsifiers in different solvents are recorded in table I where it can be seen that all emulsifiers are soluble in both oil and ethanol at $75^{\circ} \mathrm{C}$. Generally, hydroxy propenyl stearate and palmitate are insoluble with different degrees in all solvents at $25^{\circ} \mathrm{C}$ while they are soluble in oil and ethanol only at $75{ }^{\circ} \mathrm{C}$ and insoluble in the rest of solvents at this temperature.

Water seems not to be the suitable solvent for solubility of these mentioned emulsifiers. The insolubility of these emulsifiers in water suggests a non polar nature, while the solubility of some emulsifiers in oil indicate that these emulsifiers can be blended with lipids during formation of food system without employing organic solvents (13). Figure 1 shows that $\mathrm{pH}$ values of the five emulsifiers are alkaline in character which agree with those of 
sorbitol fatty acids reported by (14). Melting point, as shown in Figure 2, indicates that the value concerning hydroxy propylenyl stearate is more or less double of those of laurate and palmitate, while oleate and linoleate are liquid emulsifiers. Surface tension of the five emulsifiers are drawn in Figure 3. Those of stearate, linoleate and laurate are more or less the same as the value of hydroxy propylenyl palmitate while hydroxy propylenyl oleate shows the lowest value. Those results are in close agreement with sorbitol fatty acids reported by (14).

Table I

Solubility of some synthetic emulsifiers

\begin{tabular}{ccccccc}
\hline \multirow{2}{*}{ Solvent } & \multirow{2}{*}{ Temp. $\left(^{\circ} \mathrm{C}\right)$} & \multicolumn{5}{c}{ Compounds } \\
\cline { 3 - 7 } & & (1) & (2) & (3) & (4) & (5) \\
\hline \multirow{2}{*}{ Water } & 25 & I & SC & SC & SS & SS \\
& 75 & SS & C & C & PS & PS \\
Ether & 25 & SS & SS & S & S & S \\
P. ether & 75 & PS & PS & S & S & S \\
(40/60) & 25 & SS & PS & S & S & S \\
& 75 & PS & S & S & S & S \\
n-Hexane & 25 & SS & SS & S & S & S \\
& 75 & PS & PS & S & S & S \\
Cotton seed oil & 25 & I & I & S & S & S \\
& 75 & S & S & S & S & S \\
\multirow{2}{*}{ Ethanol } & 25 & PS & PS & S & S & S \\
& 75 & S & S & S & S & S \\
\hline
\end{tabular}

(1) Hydroxy propylenyl stearate

(2) Hydroxy propylenyl palmitate

(3) Hydroxy propylenyl laureate

(4) Hydroxy propylenyl oleate

(5) Hydroxy propylenyl linoleate

I = Insoluble

$\mathrm{PS}=$ Partialy soluble

$\mathrm{SS}=$ Springly soluble

$\mathrm{S}=$ Soluble

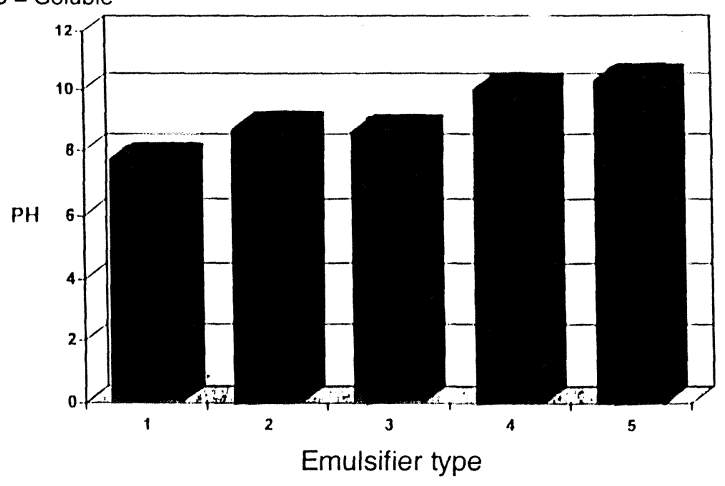

1 Hydroxy propylenyl stearate

2 Hydroxy propylenyl palmitate

3 Hydroxy propylenyl laureate

4 Hydroxy propylenyl oleate

5 Hydroxy propylenyl linoleate

Figure 1

$\mathrm{pH}$ values of emulsifiers

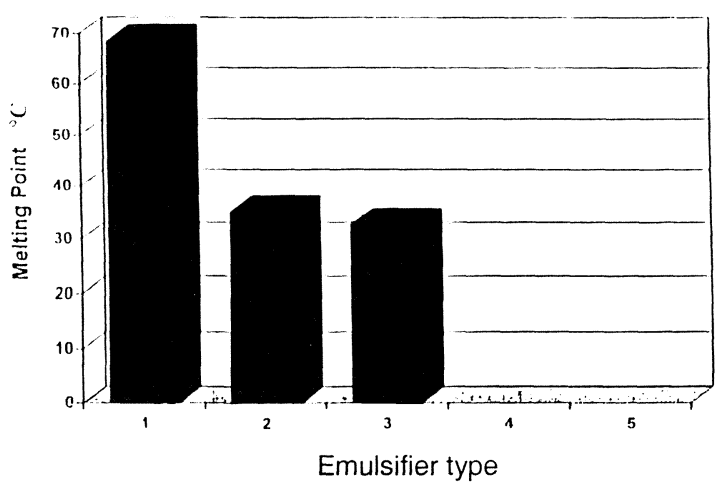

Figure 2

Melting points $\left({ }^{\circ} \mathrm{C}\right)$ of emulsifiers

(See Figure 1 for emulsifier types)

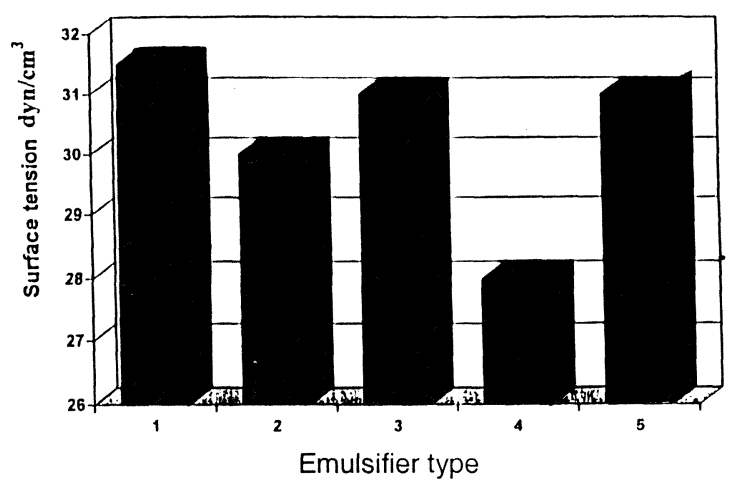

Figure 3

Surface tension $\left(\mathrm{dyn} / \mathrm{cm}^{3}\right)$ of emulsifiers

(See Figure 1 for emulsifier types)

Viscosity of hydroxy propylenyl stearate is more or less double the value of those of linoleate and oleate. Hydroxy propylenyl laurate has the lowest viscosity value and that of palmitate is much higher than that of laurate (Figure 4). Shear stress of hydroxy propylenyl stearate is about three times of that of linoleate and oleate and about four times of that of laurate and palmitate as refere in Figure 5. Emulsifying power values are given in Figure 6, which shows that all emulsifiers tested have more or less the same value. On the other side the HLB range from 3.4 HLB to $6.2 \mathrm{HLB}$ (Figure 7) so these emulsifiers promote or stabilize $\mathrm{W} / \mathrm{O}$ emulsions $(15,16)$. The relation between both shear stress to viscosity and emulsifying power to HLB are more or less parallel to each other as shown in Figures 8 and 9. From Figures (10-14), concerning the infrared spectra, it can be stated that:

- Broad band appears for streching vibration of O-H group absorbed near $3600-3400 \mathrm{~cm}^{\wedge}-1$.

- Forked band for streching vibration band for $\mathrm{C}-\mathrm{H}$ group absorbed near $3000-2800 \mathrm{~cm}^{\wedge}-1$ for methylene and methyl groups. The symmetrical bending vibration for $\left(\mathrm{CH}_{3}\right)$ occures near 1373 $\mathrm{cm}^{\wedge}-1$ and assymmetrical bending vibration near $1450 \mathrm{~cm}^{\wedge}-1$. 
- O-H bending vibration in region of 1420-1300 $\mathrm{cm}^{\wedge}-1$ in primary and secondary alcohol.

- $\mathrm{H}$ bending couple with $\mathrm{C}-\mathrm{H}$ wegging vibration to produce band near 1420 and secondary $1330 \mathrm{~cm}^{\wedge}-1$. C-O streching vibration in alcohols

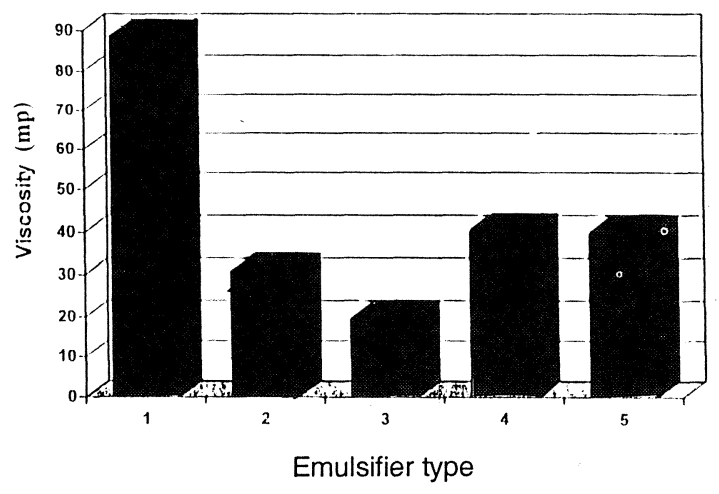

Figure 4

Viscosity ( $\mathrm{mp}$ ) of emulsifiers

(See Figure 1 for emulsifier types)

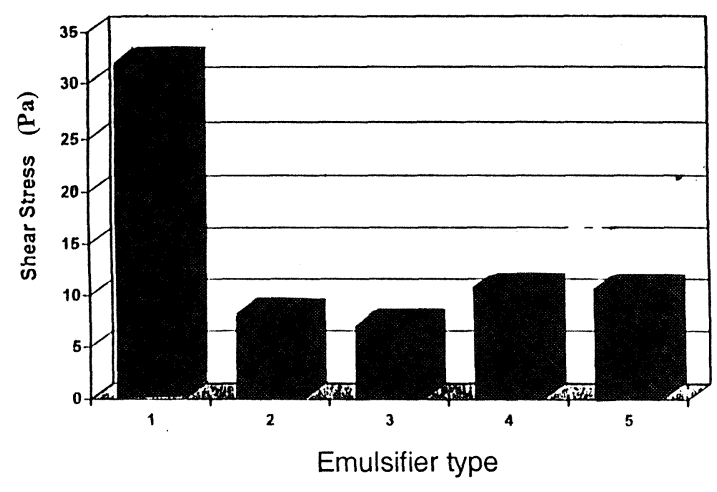

Figure 5

Shear stress $(\mathrm{Pa})$ of emulsifiers

(See Figure 1 for emulsifier types)

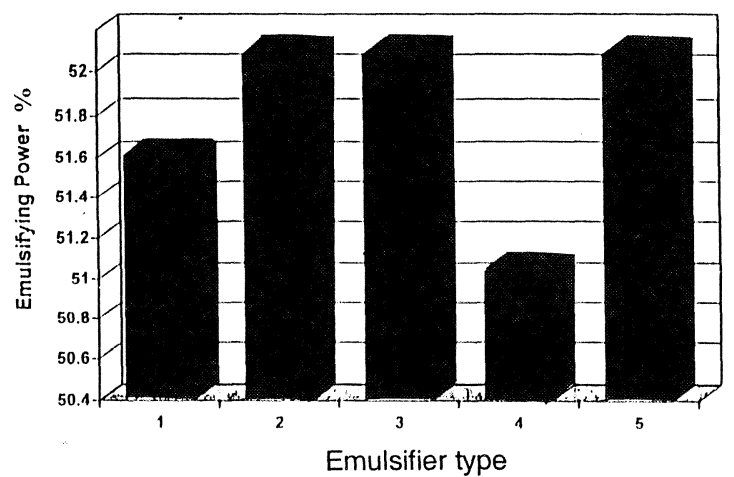

Figure 6

Emulsifying power (\%) of emulsifiers (See Figure 1 for emulsifier types) produces strong band in $1260-1000 \mathrm{~cm}^{\wedge}-1$. $\mathrm{C}-\mathrm{O}$ streching coupled with the adjacent $\mathrm{C}-\mathrm{C}$ streching vibration. This in primary alcohol gives better vibration. Streching vibration of $\mathrm{C}=\mathrm{O}$ of acid and ester absorbed near $1715 \mathrm{~cm} \sim 1$.

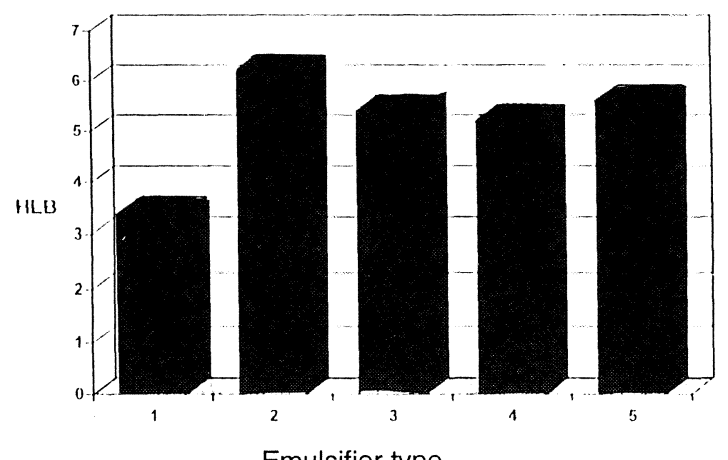

Emulsifier type

Figure 7

Hydrophile - linophile balance (HLB) of emulsifiers (See Figure 1 for emulsifier types)

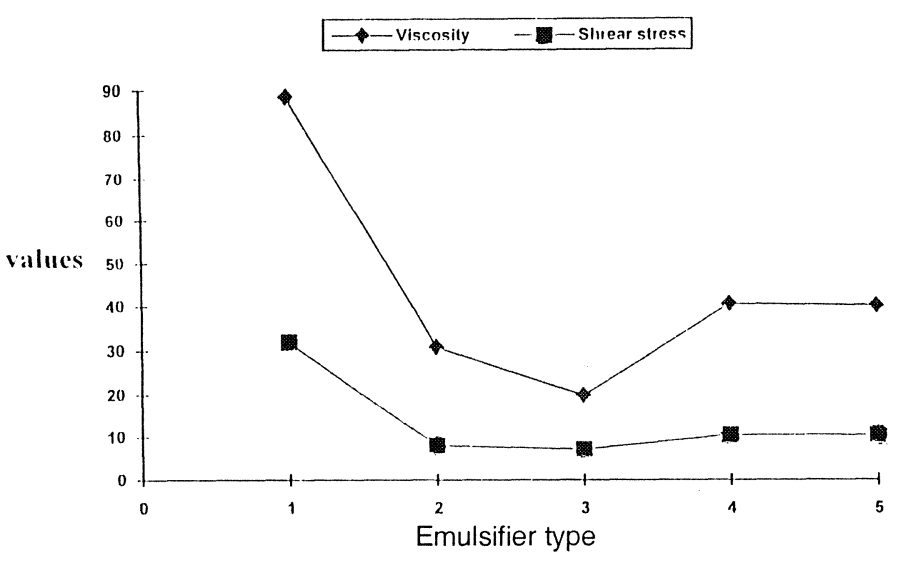

Figure 8

The relationship between the Shear Stress and Viscosity

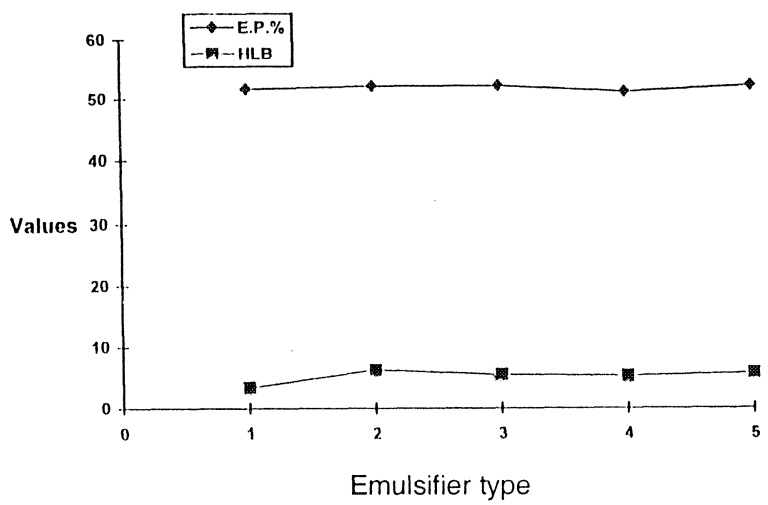

Figure 9

The relationship between Emulsifying Power Percentages and Hydrophilic Lipophilic Balance 


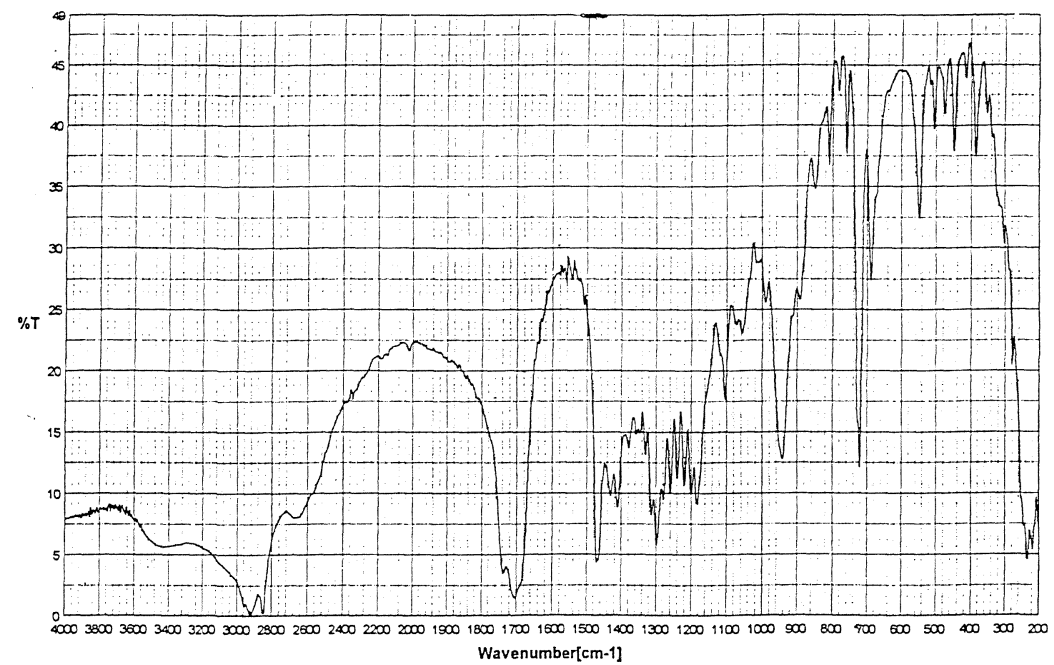

Figure 10

Infra red spectrum of hydroxy propylenyl stearate

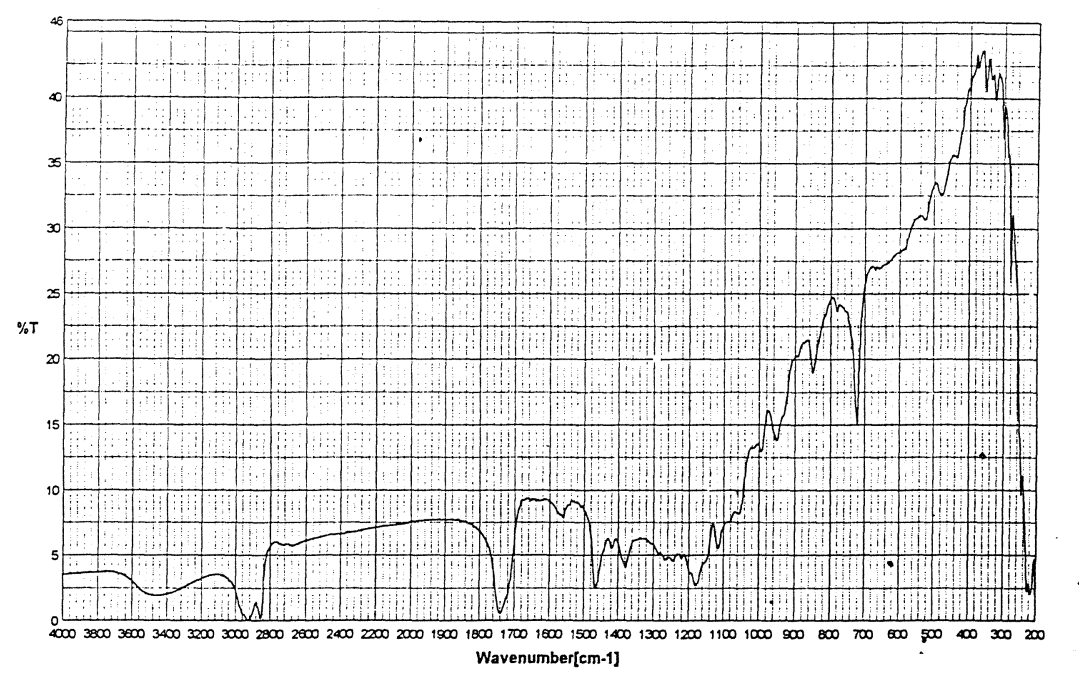

Figure 11

Infra red spectrum of hydroxy propylenyl palmitate

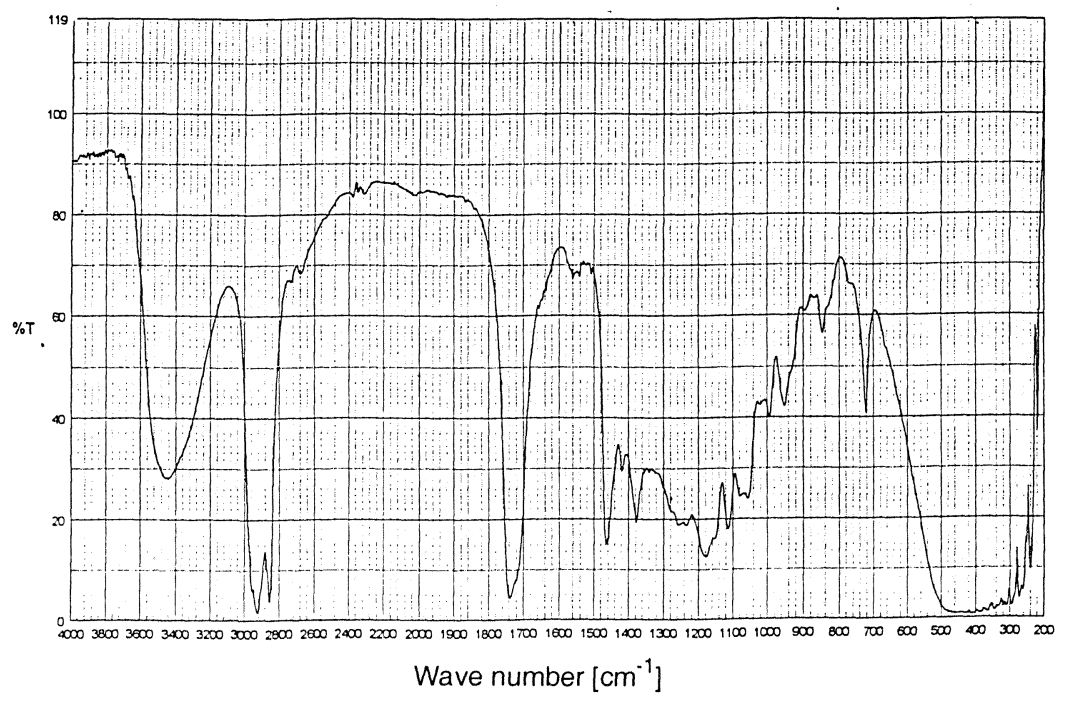

Figure 12

Infra red spectrum of hydroxy propylenyl laureate 


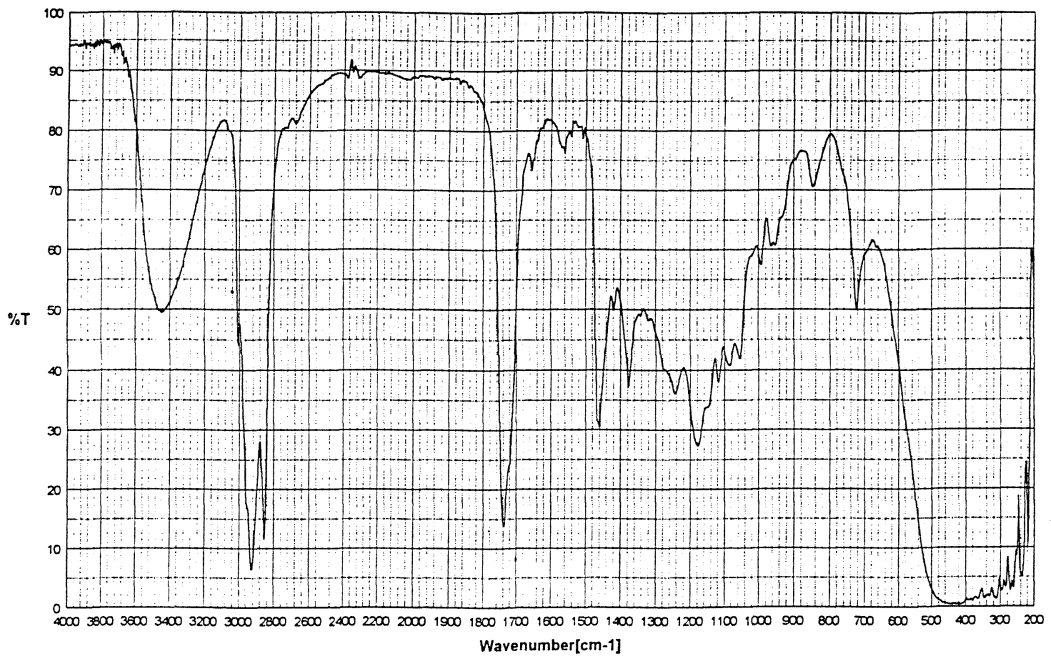

Figure 13

Infra red spectrum of hydroxy propylenyl oleate

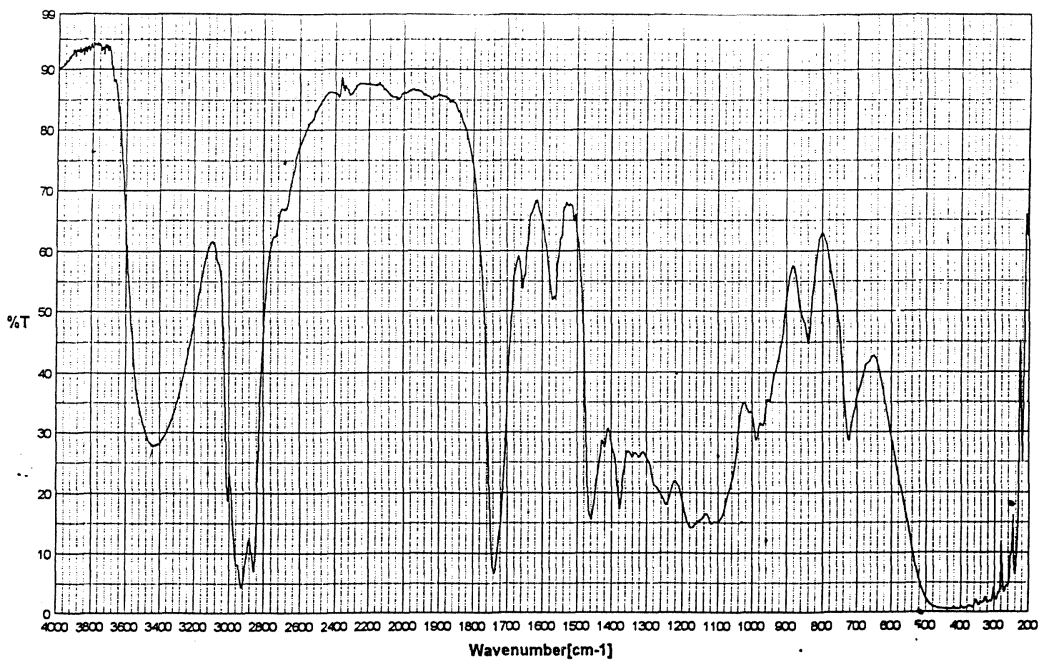

Figure 14

Infra red spectrum of hydroxy propylenyl linoleate

\section{REFERENCES}

1. Akoh, C.C. and Chigozie, V.N. (1992).-«Emulsification properties of polyesters and sucrose ester blends II: Alkyl glycoside polyesters".- Journal of the American Oil Chemists'Society 69 (1), 14-19.

2. Akoh, C.C. (1992).- «Emulsification properties of polyesters and sucrose ester blends I: Carbohydrate fatty acid polyesters".- Journal of the American Oil Chemists'Society 69 (1) 9-13.

3. Breyer, L.M. and Walker, C.E. (1983).-—Comparative effects of various sucrose-fatty acid esters upon bread and cookies"._-Journal of Food Science 48, 955-958.

4. Ebeler, S.E. and Walker, C.E. (1983).- «Cereal Chem».$60,270$.

5. Pomeranz, Y. (1981).—«lbid».-58, 190

6. Akoh, C.C. and Swanson, B.G. (1989).-—Synthesis and properties of alkyl glycoside and stachyose fatty acid polyesters".-Journal of the American Oil Chemists'Society 66, 1295-1301.

7. Alexander, A.E. and Haytex, J.B.- «Physical Methods of Chemistry".-John Wiley and Sons, New York 1971 , pp. 501-655.

8. Lutton, E.S. (1950).- - «Review of the polymorphism of saturated even glycerides".- Journal of the American Oil Chemists'Society 27, 276-281.

9. Othmer, K. (1965)._«Encyclopedia of Chemical Technol».
10. Tobias, J. and Tracy, P.H. (1950).- «Basic viscosity of ice cream mixes ice cream».-Tr. J. 46, 183.

11. Titus, T.C., Wiancko, N.N., Barbour, H.F. and Mickle, J.B. (1968).- — Emulsifier efficiency in model systems of milk fat or soybean oil and water».-Food Technology 22, 115-117.

12. Akoh, C.C. and Swanson, B.G. (1987).- «One-stage synthesis of raffinose fatty acid polyesters".-Journal of Food Science 52 (6) 1570-1576.

13. Feuge, R.O., Zeringue, H.J., Weiss, T.J. and Brown, M. (1970). - «Preparation of sucrose esters by interesterification".--Journal of the American Oil Chemists' Society 47, 56-60.

14. El-Shattory, Y., Saadia, M. Aly and Megahed, M.G. (1995).- «Performance characteristics of some synthetic emulsifiers".-SOFW Journal 121 (10) 762.

15. Nawar, W.W. (1985).- «Food Chemistry».-Edited by O.R. Fennema, Marcel Dekker, Inc., New York, pp. 139-244.

16. Gupta, R.K., James, K.A. and Smith, F.J. (1983)."Sucrose esters and sucrose ester/glyceride blends as emulsifiers".-Journal of the American Oil Chemists'Society 60, 862-869. 